
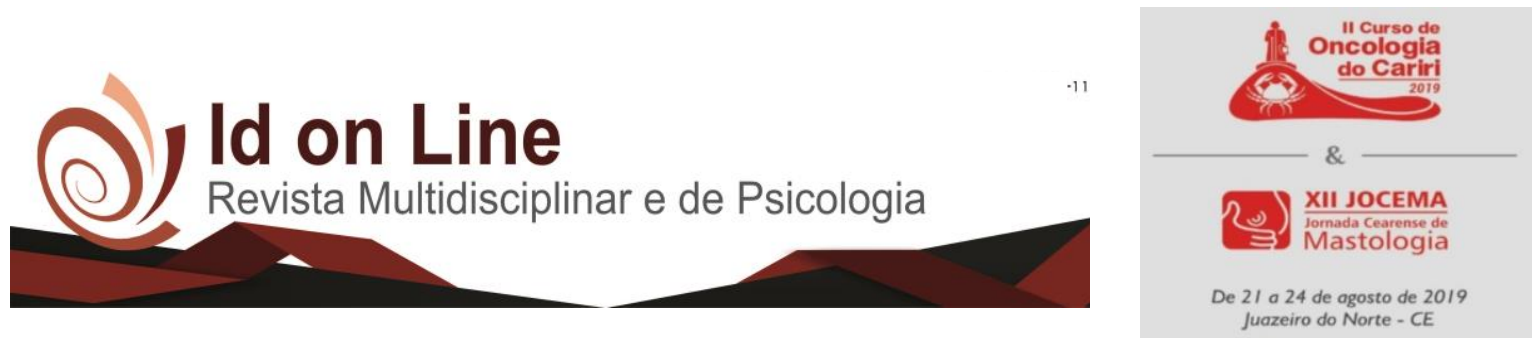

DOI: 10.14295/idonline.v13i46.2008

Resumo

\title{
DIETA CETOGÊNICA COMO ESTRATÉGIA PARA TRATAMENTO ONCOLÓGICO: COMPRAVAÇÃO CIENTÍFICA?
}

\author{
Suanam Altair Tavares de Menezes ${ }^{1}$, Ana Clara Lacerda Cervantes de Carvalho ${ }^{1}$, Karina Morais Borges ${ }^{2,}$ \\ Renata Andriola Colares ${ }^{2}$, Victor Pinheiro Gomes e Albuquerque ${ }^{2}$, Mariana Machado Bueno ${ }^{3}$
}

Introdução: Com o crescimento de mídias sociais veio também à disseminação de informações sem comprovação científica para tratamento e cura de diversas doenças, incluindo dietas milagrosas e restritivas para a cura do câncer. A dieta cetogênica consiste em substituir o consumo de carboidratos por lipídeos e reduzir a quantidade de proteínas do cardápio do paciente, simulando um estado de jejum, onde o organismo passará a utilizar ácidos graxos como sua principal fonte de energia, pois as células cancerosas necessitam de glicose para replicar-se. Objetivos: O objetivo deste estudo foi verificar através da literatura já existente a eficácia da dieta cetogênica como fator adicional no tratamento oncológico. Metodo: Trata-se de uma revisão sistemática sem metanálise, realizada em agosto de 2019, utilizando a base de dados PUBMED, empregando os descritores associados ao operador booleano (AND): Dieta. Neoplasias. Dieta Cetogênica. Foram consultadas também publicações da Sociedade Brasileira de Nutrição Oncológica (SBNO) e o parecer do Instituto Nacional de Câncer (INCA). Foram incluídos: artigos dos últimos 2 anos, artigos disponíveis na integra e artigos em inglês e português. Foram excluídos: artigos repetidos, testes em espécie animal, teses e monografias. Resultados: Foram encontrados 68 estudos, após leitura 9 enquadraram-se com o tema proposto. O INCA, a SBNO e a Sociedade Europeia de Nutrição Enteral e Parenteral (ESPEN) não recomendam dieta cetogênica, orientam que a alimentação do paciente oncológico deva ser baseada em evidências científicas e complementam que as recomendações energéticas para estes sejam as mesmas que para indivíduos saudáveis, variando conforme condição metabólica individual. Na maioria dos ensaios pré-clínicos, a dieta cetogênica inibiu a alta produção de glicose e a proliferação de certos tipos de tumores, alguns estudos apontam efeitos antitumorais, entretanto este tipo de dieta pode levar a caquexia devido à doença ter caráter catabólico, a evidência cientifica ainda é limitada e a possibilidade de excluir alimentos comprovadamente benéficos para o tratamento do câncer é alta. Conclusão: É provável que a dieta cetogênica crie um ambiente desfavorável para replicação de células cancerígenas, no entanto é necessário elucidar melhor o mecanismo de ação deste tipo de conduta como terapia e avaliar seus efeitos na prática, até o presente momento os resultados são inconsistentes e necessitam de mais estudos clínicos controlados.

Palavras-chave: Dieta. Neoplasias. Dieta Cetogênica.

\footnotetext{
${ }^{1}$ Discente do curso de Nutrição, na Faculdade de Juazeiro do Norte - FJN, Juazeiro do Norte, CE, Brasil.

${ }^{2}$ Nutricionista, Docente do curso de Nutrição, na Faculdade de Juazeiro do Norte - FJN, Juazeiro do Norte, CE, Brasil;

${ }^{3}$ Orientadora, Nutricionista, Docente do curso de Nutrição, na Faculdade de Juazeiro do Norte - FJN, Juazeiro do Norte, CE, Brasil;

Autor correspondente: Sussu.tavares@ hotmail.com.
} 


\section{Referencias}

CHUNG, H.Y.; PARK, Y. K. Rationale feasibility and acceptability of ketogenic diet for cancer treatment. Journal of cancer prevention. v. 22, n. 3, p. 127, 2017. DOI:10.15430/JCP.2017.22.3.127.

COHEN, C. W.; FONTAINE, K. R.; AREND, R. C.; ALVAREZ, R. D.; LEATH III, C. A; HUH, W. K.; BEVIS, K.S.; KIM, K.H.; STRAUGHN, J.M.; GOWER, B. A. COHEN, A ketogenic diet reduces central obesity and serum insulin in women with ovarian or endometrial cancer. The Journal of nutrition, v. 148, n. 8, p. 1253-1260, 2018. DOI: 10.1093/jn/nxy119.

INCA. Publicações e notas técnicas. Posicionamento do Instituto Nacional De Câncer José Alencar Gomes da Silva acerca da orientação de dietas restritivas durante o tratamento oncológico - INCA, 2019. Disponível em: https://www.inca.gov.br/sites/ufu.sti.inca.local/files//media /document//posicionamento_acerca_de_dietas_restritivas.pdf

KLEMENT, R. J. Fasting, fats, and physics: combining ketogenic and radiation therapy against Cancer. Complementary medicine research. v. 25, n. 2, p. 102-113, 2018.

KLEMENT, R.J.; PAZIENZA, V. Impact of Different Types of Diet on Gut Microbiota Profiles and Cancer Prevention and Treatment. Medicina. v. 55, n. 4, p. 84, 2019. DOI: 10.3390/medicina55040084.

SBNO. Sociedade Brasileira de Nutrição Oncologica. Atualizações cientificas: Dieta Cetogênica e Câncer - SBNO, 2017. Disponível em: https://www.sbno.com.br/Materia/Post?year=2017 $\&$ month $=4 \&$ title $=$ DIETA\%20CETOG\%C3\%8ANICA\%20E\%20C\%C3\%82NCER

VERGATI, M.; KRASNIQI, E.; MONTE, G.D.; RIONDINO, S.; VALLONE, D.; GUADAGNI, F.;FERRONI, P.; ROSELLI, M. Ketogenic Diet and Other Dietary Intervention Strategies in the Treatment of Cancer. Current medicinal chemistry. v.24, n.12, p.1170-1185, 2017. DOI: 10.2174/0929867324666170116122915.

WEBER, D.D.; AMINZADEH-GOHARI, S.; TULIPAN, J.; CATALANO, L.; FEICHTINGER, R. G.; KOFLER, B. Ketogenic diet in the treatment of cancer-where do we stand?. Molecular Metabolism. 2019. DOI: 10.1016/j.molmet.2019.06.026.

ZICK, S. M.; SNYDER, D.; ABRAMS, D.I.; Pros and Cons of Dietary Strategies Popular Among Cancer Patients. Oncology. v. 32, n. 11, 2018. 